\title{
Producing 3D Animation Teaching Materials - A Case Study of the Huge Differences between Male and Female Wealth Management
}

\author{
Tingsheng Weng
}

\begin{abstract}
Wealth management education has invariably been a concern that cannot be neglected. The information received and risk appetite of genders in wealth management are different, resulting in different wealth management habits and investment behaviors. There are differences in the wealth management methods and investment behaviors between males and females. This study adopts three software applications, Animaker, ZEPETO, and PowerDirector, to produce three different 3D animation teaching materials on the huge differences of wealth management practices between men and women. If students have a deep understanding of the differences between men and women in wealth management and investment behavior, they can fully perceive the importance of personal and family wealth management.
\end{abstract}

Index Terms-Wealth management habit, 3D, animation, investment behavior.

\section{INTRODUCTION}

Correct wealth management education is a practical problem that the government, schools, society, and families must address. The United States, Japan, and other countries attach great importance to wealth management education and put it into practice as an important educational content [1]. Bryant, Stone, and Wier [2] argued that personal wealth management knowledge affects their wealth management attitude. Xiao, Tang, and Shim [3] pointed out that if college students are willing to control their cognition of personal wealth management, then they will be more satisfied with their wealth management situation and have less debt, and that wealth management is positively related to physical health, mental health, and people's lives. Wealth management literacy has improved wealth management decision-making [4]. The level of wealth management knowledge is positively correlated to people's income and retirement preparation [5]. The wealth management knowledge and habits that students develop in school will be part of their adult life, and students who lack wealth management knowledge tend to have more negative perceptions about wealth management and make mistakes in financial decision making [6].

Adams and Funk [7] held that the behavior and strategic choices of risk appetite will differ from men to women, which leads to different gender investment behaviors and financial habits. Men will be more inclined to choose bold

Manuscript received July 12, 2019; revised January 13, 2020.

Ting Sheng Weng is with National Chiayi University, Taiwan (e-mail: politeweng@mail.ncyu.edu.tw). investment projects, while women are more conservative, and in favor of medium-term and long-term stable investments. Generally, gender is not considered the primary influencing factor of wealth management behavior; however, this is not the truth.

The application of animation to education and the advocacy of popular science has been a trend in recent years [8]. Xiao [9] argued that the application of multimedia is of great help to education. 3D visualized and 3D simulated animation textbooks provide a more intuitive experience through new knowledge and technologies, in order that learners can be more immersive to absorb more advanced and professional knowledge and skills, which will enable students to stay closer to what they have learned and promote the knowledge of media applications in an efficient manner. Therefore, this study aims to foster better philosophy of wealth management and investment for students through 3D animation (multimedia education).

\section{RESEARCH MOtIVES AND PURPOSES}

Wealth management knowledge can be acquired through wealth management education. Hira and Loibl [10] pointed out that when people receive wealth management education, they can improve their financial literacy. As such, they can understand their current situation and possible financial situation in the future, increase their confidence, and improve their job satisfaction.

Walczak, Pienkowska-Kamieniecka et al. [11]-[13] suggested that differences indeed exist in the wealth management habits and investment behaviors of genders. The main difference lies in the fact that males are more inclined to choose bold investment projects, while women are more conservative, and in favor of medium-term and long-term stable investment. In terms of wealth management behavior, the objective of male wealth management is usually to increase net worth and improve their current quality of life, while female wealth management aims to provide a guarantee for their post-retirement life and invest in the future, thus, the wealth management of genders focuses on different periods of time. The consumption habits of women are more likely to cause chaos in life than those of men. Males are more peaceful and less emotional in response to the changes of investment market, while women are more likely to be emotional and worried when changes take place. However, it is also pointed out that some men are so overconfident that they fail to listen to suggestions, which leads to problematic investment. In contrast, women are more cautious and open 
to more suggestions for the sake of investment security.

According to Byrnes, Miller, and Schafer [14], there are three main differences in wealth management between men and women: risk appetite, investment behavior, and wealth management knowledge. Therefore, it is very important for students to understand the importance of wealth management behavior, in order to develop personal economic behaviors as early as possible. The different methods and objectives of wealth management and financial products for different wealth management behaviors can exert positive impact on the future personal economic behavior of college students. Literature shows that there are differences between men and women in wealth management and investment behavior. Therefore, 3D animation is applied to create virtual characters representing men and women, which show the knowledge of wealth management and investment behavior, describe the wealth management and investment behavior of men and women, improve students' understanding of the differences between men and women in wealth management behavior, and enhance their financial planning ability and wealth management knowledge.

\section{LITERATURE REVIEW}

\section{A. Multiple Differences of Wealth Management between Males and Females}

The Organization for Economic Co-operation and Development holds that financial literacy is a combination of person OECD al awareness, knowledge, skills, attitudes, and necessary behavior of wealth management to make correct financial decisions and ultimately achieve personal financial objectives [15]. Grable and Joo [16] took American college students as the research subjects, and discussed their credit card debt, financial behavior, and financial pressure. The results indicated that students' subjective financial literacy had a significant impact on their financial behavior. People with higher financial literacy can manage their money more effectively [5]. If people lack the ability of financial planning and risk management, or do not foster proper attitude and skills for wealth management, they are prone to make improper financial decisions. Therefore, governments should provide appropriate financial education for their citizens [17].

\section{1) Difference of risk appetite}

Risk appetite is a concept that combines economics, finance, and psychology to explain the behavior of consumers and investors in uncertain situations. Risk aversion is to compare how reluctant a person is to accept a deal with uncertain returns or another deal with more security and lower expected returns; for example, an investor featuring risk aversion may choose to deposit his or her money in bank for a lower, but definite, interest rate, rather than put it in the stock market and bear the risk of loss while achieving higher expected returns. This concept, in contrast to a person's risk aversion, is called "risk taker".

Byrnes, Miller, and Schafer [14] suggested that there are differences in risk taking between men and women. Walczak and Pienkowska-Kamieniecka [11] pointed out that there are significant differences in financial behaviors between men and women. Men use products and services available in the financial market more frequently, such as debit cards, or investment in stocks or bonds. They are also more willing to take risks. Satpathy and Gender and Finance [18] also proposed the differences of risk aversion between men and women. They took MBA students as the subject of analysis, and found that women feature risk aversion, as compared to men, while men feature more risk appetite in financial decision-making.

\section{2) Difference of investment behavior}

Bauer, Braun, and Olson [19] believed that wealth management can improve students' savings and investment, reduce debt, and avoid bankruptcy. Blalock, Tiller, and Monroe [20] found that students with financial knowledge were less likely to have poor consumption behaviors. Hsiao and Chih [21] used the questionnaire survey method in their report "The Impact of Gender on Financial Knowledge and Financial Behavior". According to their analysis, many financial conducts of people in the face of financial anomalies that violate traditional financial theories are not "rational", as considered by traditional financial theories. As a result, behavior finance gradually emerges in an attempt to learn and identify human psychology in the financial market. The understanding and reasoning of finance significantly differ between males and females. It is pointed out that: 1) the level of financial knowledge of men is slightly lower than that of women; 2) gender has no significant impact on the financing and wealth management of people; 3) Taiwanese women are more active in pension planning than men; 4) male students are less likely to purchase life insurance and health care than female students; 5) males are more likely to bear excessive credit loans and overdraft than females.

Bernasek and Shwiff [13] argued that the different investment behavior patterns of males and females will affect the quality of life of the elderly after retirement.

Tsai's [22] research on "Exploring the Philosophy of Wealth and Investment of the Young After the Financial Crisis" found that men and women share equal access to financial information in this era of information explosion, and investment behaviors may differ from men to women due to the quantity, profit, and risk of investment. In addition, both men and women prefer to choose financial instruments of which they have more knowledge.

Hsu, Huang, and Hung [23] mentioned in "Gender and Investment Behavior Errors" that gender is strongly correlated to behavioral errors. Males have stronger definite overconfidence, control illusions, and identification of errors than females do. Female investors are less likely to regret their investments than male investors. Empirical results confirm that gender difference exist in investment behavior errors.

\section{3) Difference of wealth management literacy}

Joo and Grable [24] pointed out that financial literacy has a significant influence on financial behavior. When people have the right financial attitude, they will be more satisfied with their financial situation. Jump \$tart Coalition [25] argued that financial literacy refers to the ability to use knowledge and skills. For a lifetime of financial security, all 
people should effectively manage their financial resources. This involves financial knowledge, presenting a positive, confident attitude, and having the ability to plan and make decisions.

Tseng [26] used the questionnaire analysis method in his report titled "Planning of Fostering Financial Literacy and Ability of College Students". In the analysis, Tseng wrote: The impact of gender on the financial literacy for college students reaches a significant level, indicating that there is a significant difference in financial literacy between students of different genders, and that female students are better than male students.

Baron-Cohen [27] pointed out that there are differences between men and women in thinking and memory. In terms of learning and absorbing knowledge, the "financial responsibility and decision-making" of females are better than males, while the "self-discipline" of "financial attitude" of males is better than females. Females are more flexible to take the wealth management suggestions given by their parents and change their financial literacy, which may be due to the fact that females get along and interact with their parents better, from whom they learn the financial knowledge and skills to improve their personal financial knowledge. Male students are more self-disciplined than female students; male students can take more into consideration and avoid waste when shopping [28].

The above literature shows that young males and females show differences in wealth management, risk appetite, financial literacy, and investment behavior.

\section{B. Impact of 3D Animation on Wealth Management of the Young}

Static charts on books and blackboards may not be enough for students to fully understand wealth management, while repeated animation is obviously conducive to the improvement of teaching effects [29]. In character animation, understanding the relationship between the function of expression and emotion can help understand the information received by the audience [30].

Lo and Chang [31] mentioned that animation can spread financial knowledge and enhance people's understanding of property activities. Lee, $\mathrm{Wu}, \mathrm{Hou}$, and Lo [32] designed CAI software that contains "money concept", "increasing income and cutting expenditure", and "savings planning." Their results show that CAI software can improve students' learning performance of financial education, including immediate, maintenance and generalization effects, and has good social validity. However, there is little research on making financial related teaching materials with $3 \mathrm{D}$ animation. According to this study, the 3D animation teaching materials can help students to learn repeatedly, and thus, deepen their understanding of what they have learned.

\section{RESEARCH METHOD}

\section{A. Research Tools}

This study used software including Animaker, ZEPETO and PowerDirector to produce animation.

Animaker can design high-quality animated films with various input, such as text, dynamic effects, music, and images. Animaker software is used for the beginning, transit effects, and background of the film, while ZEPETO is used to create vivid figures, record action, and establish dialogue text boxes.

PowerDirector is used to import, edit, and export videos. ZEPETO characters are integrated to the editing of the background, dubbing, and adding opening effects, and then, the film is output.

Animation imports data regarding savings insurance,

funds, and investment commodities, and uses voice and subtitled dialogues to present the lively plots created by the body movements of characters, which aim to draw the attention of listeners and help them develop better wealth management habits.

Many good actors are good at changing their facial expressions to match the emotions of the characters in the play, which is called "acting skill". Similarly, facial expressions in animation will affect the viewers. In this study, we set up a design to control the emotions of the characters. If a certain facial expression is missing, then the emotion may not be right. In the process of designing a character's facial expression in line with the plot, we tried our best to show the change of emotional expression.

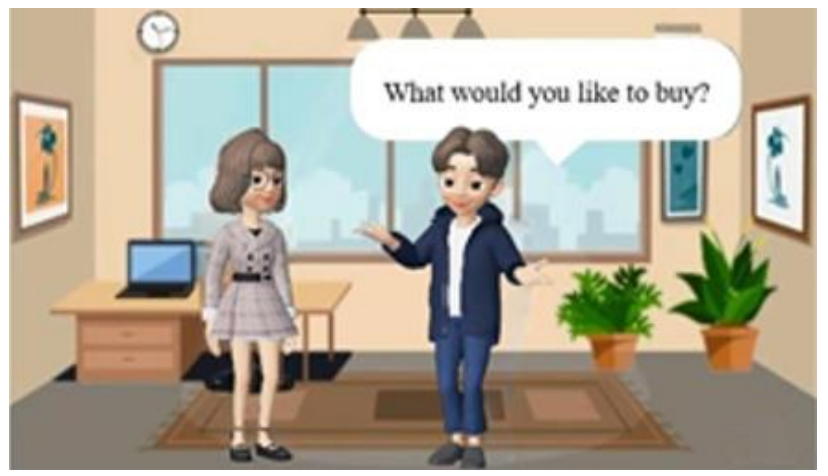

Fig. 1. 3D character conversation.

In animation, it is not easy to give the character reasonable actions. Thus, in the design the movements of the character should make people feel smooth and natural. However, at this stage, the character may only be a moving object, and the character needs to perform reasonable actions to show the thinking and emotional reactions, so that the viewers will be willing to accept and believe. In this study, the dialogue plays of the 3D dynamic characters' lives are used to increase students' concentration on financial investment knowledge. By calculating the rates of return and claim amount of savings insurance, they can have a better understanding of the topic (Fig. 2-3).

The animation also includes an introduction regarding the risk of different investment instruments, such as bank deposits, insurance, bonds, funds, foreign exchange, stocks, and futures (Fig. 3). The cumulative payment of savings insurance is compared with accident claims and contract termination (Fig. 4). The animation also explains the functions of credit cards, and calculates the consumption interest rate of credit cards, in order that consumers can use credit cards for delayed payments, points, the exchange of air mileage, and cash for benefit (Fig. 5). The examples of the consumption, payment, and revolving interest of credit cards 
are shown in Fig. 6. Fig. 7 shows the differences between men and women in their thoughts regarding investment and savings. Various differences exist in financial habits between men and women, including risk appetite, shopping pattern, investment behavior, enthusiasm for investment knowledge, and the outlook of money. Men show more risk-taking in investment, more rational in consumption, and attach more importance to learning investment knowledge, while women are more risk-averse and emotional, and men value the concept of savings. Careful wealth management is also suggested in the animation.

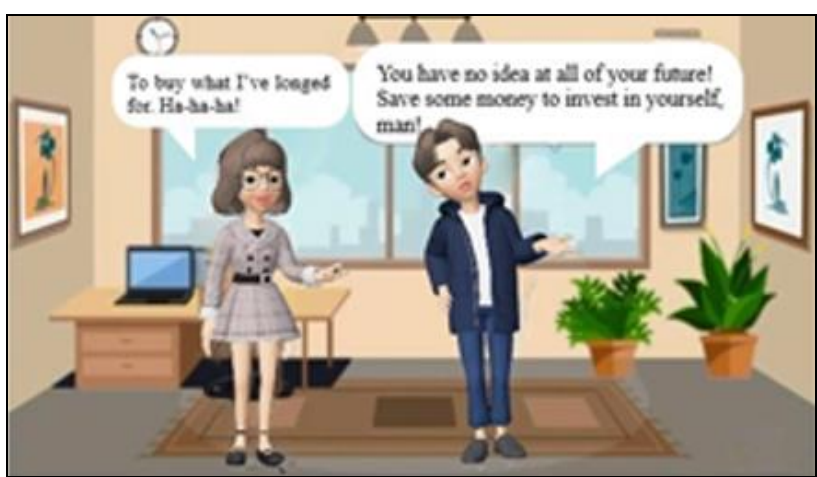

Fig. 2. 3D character conversation.

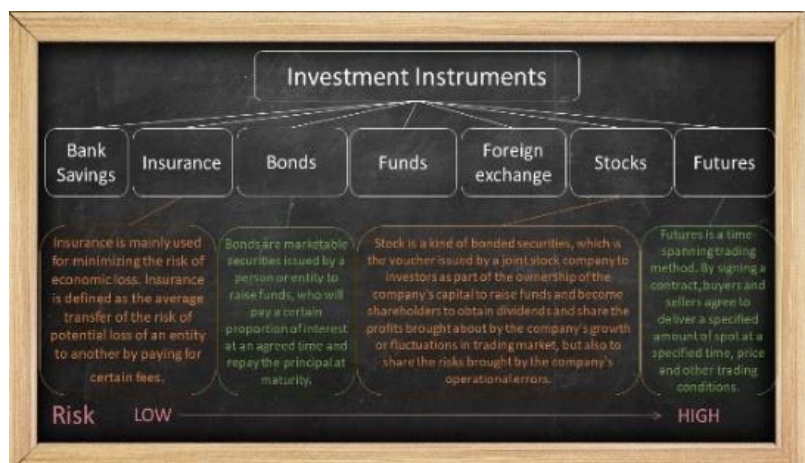

Fig. 3. Introduction of investment instruments.

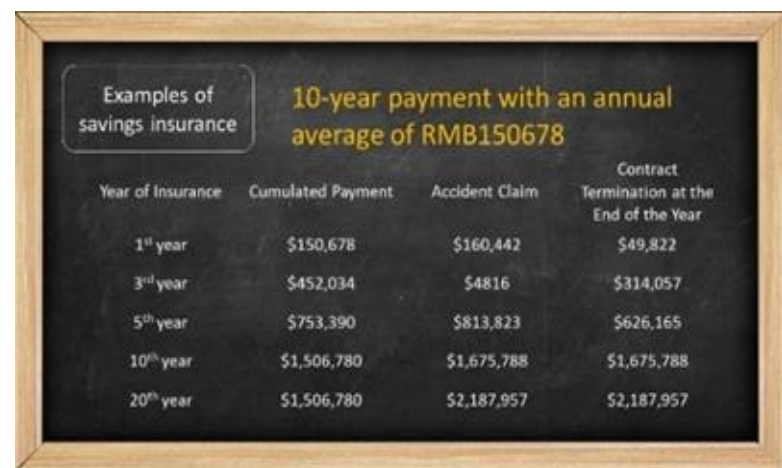

Fig. 4. Calculation of savings insurance.

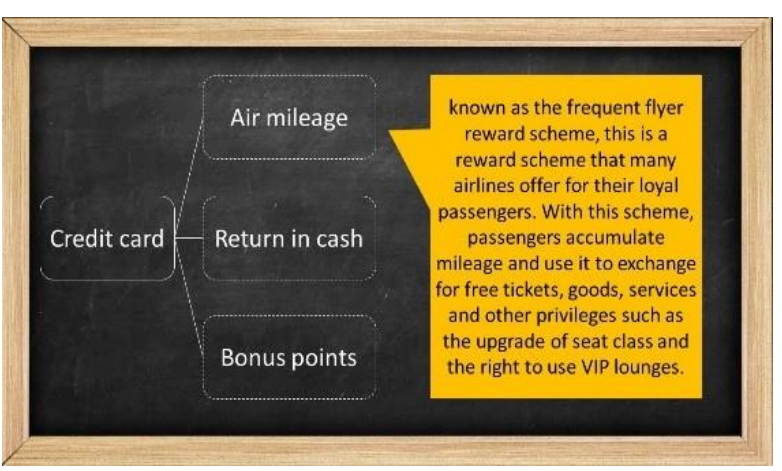

Fig. 5. Introduction of credit cards.

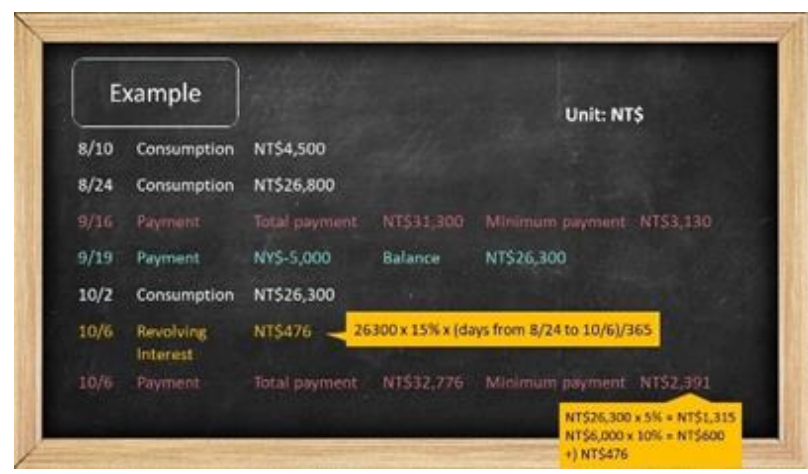

Fig. 6. Calculation of credit cards

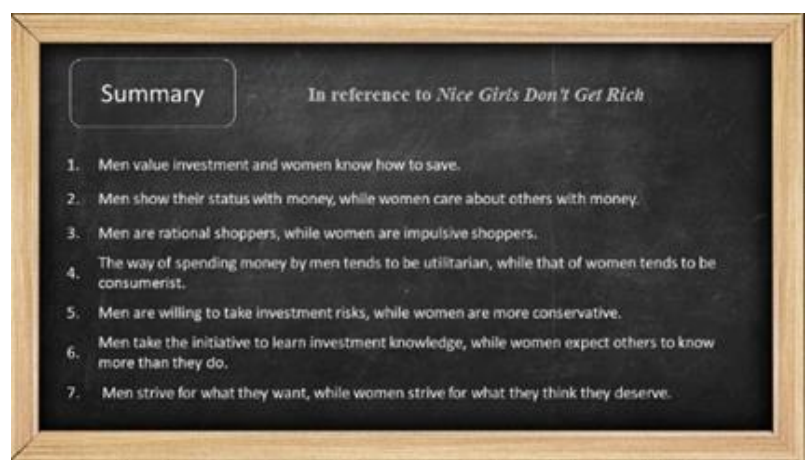

Fig. 7. Differences of wealth management in males and females.

\section{Conclusion And Suggestions}

The influence of 3D animation on youth financial management is not just reflected in the animation itself. Students' willingness to accept and understand wealth management knowledge and the degree of their focus in class have visible changes. In this film, situational animation spurs students' learning motivation, increases their focus in the classroom, widely discusses the differences between men's and women's investment behavior, and improves the effect of students' financial management. For example, they understand the differences in risk aversion, financial habits, etc. It is found that men prefer investment with high risk and return, while women prefer investment with low risk and stable return.

This study suggests that follow-up studies interpret the details of wealth management and investment knowledge, make short serial films to attract visitors to gain more insight into the similarities and differences between men and women in wealth management, and analyze the impact and effectiveness of short serial films regarding the wealth management of both genders on students

\section{CONFLICT OF INTEREST}

The authors declare no conflict of interest.

\section{ACKNOWLEDGEMENT}

The authors appreciate the comments of the review committee. This study was financially supported by the Ministry of Science and Technology under grant no. MOST 106-2511-S-415-013-MY2.

\section{REFERENCES}

[1] L. Orton, "Financial literacy: Lessons from international experience," CPRN Research Report, vol. 9, pp. 1-63, 2007. 
[2] S. M. Bryant, D. N. Stone, and B. Wier. (2006). Financial attitudes: Implications for personal financial planning services (PFPSs) and financial literacy. [Online]. Available: http://ssrn.com.ezproxy.library. wisc.edu/abstract $=896101$

[3] J. J. Xiao, C. Tang, and S. Shim, "Acting for happiness: financial behavior and life satisfaction of college students," Soc Indic Res., 2008.

[4] L. Mandell, "The impact of financial education in high school and college on financial literacy and subsequent financial decision making," presented at the American Economic Association Meetings, San Francisco, CA, 2009.

[5] M. A. Hilgert, J. M. Hogarth, and S. G. Beverly, "Household financial management the connection between knowledge and behavior," Fed. Reserve Bul., vol. 89, pp. 309-322, Nov. 2003.

[6] L. L. Blalock, V. R. Tiller, and P. A. Monroe, "They get you out of courage: Persistent deep poverty among former welfare-reliant women," Fam. Relat., vol. 53, pp. 127-137, Mar. 2004.

[7] R. B. Adams and P. Funk, "Beyond the glass ceiling: Does gender matter?" UPF Working Paper Series, European Corporate Governance Institute- Finance Working Paper, 2009, pp. 2-3.

[8] Central Taiwan Science Park, "Appreciating the scientific charm in animation - The Taiwanese popular science animation exhibition held in Taiwanese technological self-made robot base," pp. 1-3, 2019.

[9] L. Xiao, "Animation trends in education," Int. J. Inf. Educ. Tech., vol. 3, pp. 286-289, Jun. 2013.

[10] T. K. Hira and C. Loibl, "Understanding the impact of employer-provided financial education on employee commitment," $J$. Consum. Aff., vol. 39, pp. 173-197, 2005.

[11] D. Walczak and S. Pienkowska-Kamieniecka, "Gender differences in financial behaviours," Inz. Ekon., vol. 29, pp. 123-132, 2018.

[12] R. B. Adams and D. Ferreira, "Women in the boardroom and their impact on governance and performance," J. Financ. Econ., vol. 94, pp. 291-309, 2009.

[13] A. Bernasek and S. Shwiff, "Gender, risk, and retirement," J. Econ., vol. 35, pp. 345-356, Jun. 2001.

[14] J. P. Byrnes, D. C. Millerand, and W. D. Schafer, "Gender differences in risk taking: A meta-analysis,” Psychol. Bull., vol. 125, pp. 367-383, 1999.

[15] Organization for economic co-operation and development, "Financial literacy: Questionnaire and guidance notes for conducting an internationally comparable survey of financial literacy," Paris: OECD, 2011.

[16] J. E. Grable and S. H Joo, "Student racial differences in credit card debt and financial behavior and stress," Coll. Student J., vol. 40, pp. 400-408, 2006

[17] M. S. Sherraden, L. Johnson, B. Guo, and W. Elliott, "Financial capability in children: effects of participation in a school-based financial education and savings program," J. Farm. Econ., vol. 32, pp. 385-399, 2011

[18] S. Satpathy, "Gender \& finance," Gender Financ Rev Ser \#7, pp. 6-11, 2018.

[19] J. W. Bauer, B. Braun, and P. D. Olson, "Welfare to well-being framework for research, education, and outreach," J. Consum. Aff., vol 34, pp. 62-81, 2000

[20] L. L. Blalock, V. R. Tiller, and P. A. Monroe, "They get you out of courage: persistent deep poverty among former welfare-reliant women," Fam. Relat., vol. 53, pp. 127-137, 2004
[21] Y. J. Hsiao and H. H. Chih, Gender Differences in Financial Literacy and Financial Behavior, NSC 102-2629-H-259-001-MY2, pp. 1-85, 2012.

[22] S. H. Tsai, "An investigation on the concept of the pursuit of enrichment and investment for the Taiwan young after the financial crisis," Chung Chou J. Mange. Hum. Sci., vol. 1, pp. 199-2111, Mar. 2011.

[23] Y. L. Hsu, P. K. Huang, and L. Y. Hung, "Gender and investment behavioral bias," Rev. Secur. Future Market., vol. 29, pp. 147-182, 2017.

[24] S. H. Joo and J. E. Grable, "An exploratory framework of the determinants of financial satisfaction," J. Fam. Econ. Issues, vol. 25, pp. 25-50, 2004.

[25] Jump\$tart coalition for personal financial literacy, National Standards in K-12 Personal Finance Education with Benchmarks, Knowledge Statements, and Glossary, January 20, 2010.

[26] Y. C. Tseng, "A study on competence indicators of financial education for college students," MOST 102-2410-H-003-066, pp. 1-28, 2013.

[27] S. Baron-Cohen, The Essential Difference: The Truth about the Male and Female Brain, Penguin, NY: Basic Books, 2003, pp. 1-4.

[28] Y. C. Tseng and F. L. Wang, "A path analysis of parents' financial teaching effects on children's financial literacy, attitude and behavior of high-school students in Taichung," Comm. Manage. Quart., vol. 18, pp. 51-74, 2017.

[29] Y. M. Yang, S. Y. Pan, L. L. Wu, Y. J. Gao, X. R. Song, J. Wu, and J. Zhao, "The design of cartoon in genetics teaching," J. Xuzhou Normal Univ. Nat. Sci. Ed., vol. 22, pp. 75-78, 2004.

[30] S. M. Huang and S. K. Chung, "The study of facial expression design in 3d computer character animation," J Lunghwa Univ Scien Techno., vol. 27, pp. 169-193, 2009.

[31] B. Lo and Y. C. Chang, "Animation financial assumption based on two-dimensional accounting model," Frien Acct., vol. 7B, pp. 57-58, 2010.

[32] L. Y. Lee, C. L. Wu, C. T. Hou, and J. S. Lo, "The effects of multimedia computer assisted instruction on the performance of financial education for elementary children with intellectual disabilities," J Res Spec Educ Assist Technol. , vol. 6, pp. 23-43, 2013.

Copyright (C) 2020 by the authors. This is an open access article distributed under the Creative Commons Attribution License which permits unrestricted use, distribution, and reproduction in any medium, provided the original work is properly cited (CC BY 4.0).

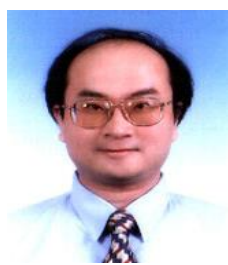

Ting Sheng Weng is an associate professor of the Department of Business Administration at National Chiayi University, Taiwan. He received his $\mathrm{Ph}$. D. in Division of Management and Information Science, Graduate School of Advanced Technology from Kinki University, Japan in 2000. He had served as visiting professor at Meiji University in Japan from 2006 through 2007. His major research interests include science technology and management, e-learning, animation, information education, technology education, MIS, and image processing. 